\title{
The LHCb VELO: \\ Status and Upgrade Developments
}

\section{Overview}

- The LHCb detector and the VELO

- VELO sensor performance

- Possible upgrade solution

- Czochralski Silicon

- Current status

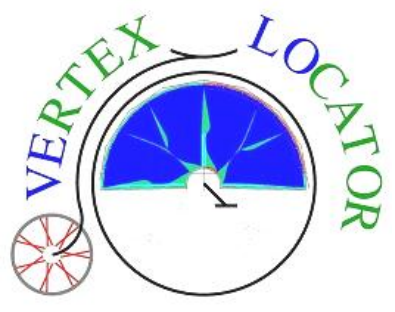

\section{Alison G Bates \\ on behalf of the LHCb VELO Group}

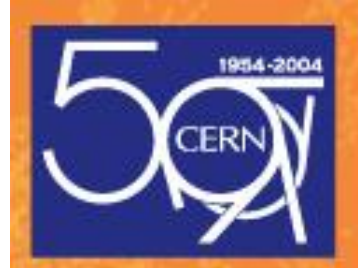

CERN (Geneva), EPFL (Lausanne), NIKHEF (Amsterdam), University of Glasgow, University of Heidelberg, University of Liverpool 


\section{LHCb \\ Aim: to study CP violation in B meson systems}

- Detector at the LHC analysing $14 \mathrm{TeV}$ proton-proton collisions

- $\sim 10^{12}$ bb pairs produced every operational year $\mathcal{L}=2 \times 10^{32} \mathrm{~cm}^{-2} \mathrm{~s}^{-1}$ with $\sigma_{\mathrm{b} \overline{\mathrm{b}}} \approx 500 \mu \mathrm{b}$

Silicon VErtex LOcator

Magnet interaction region

VELO

^ $\mathrm{RICH} 1$

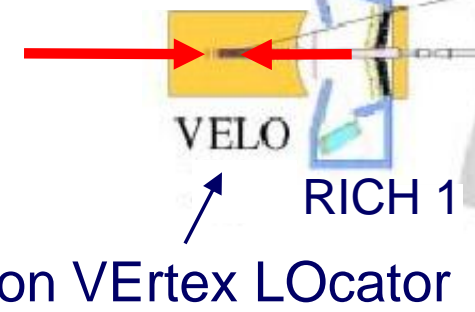

October 2004

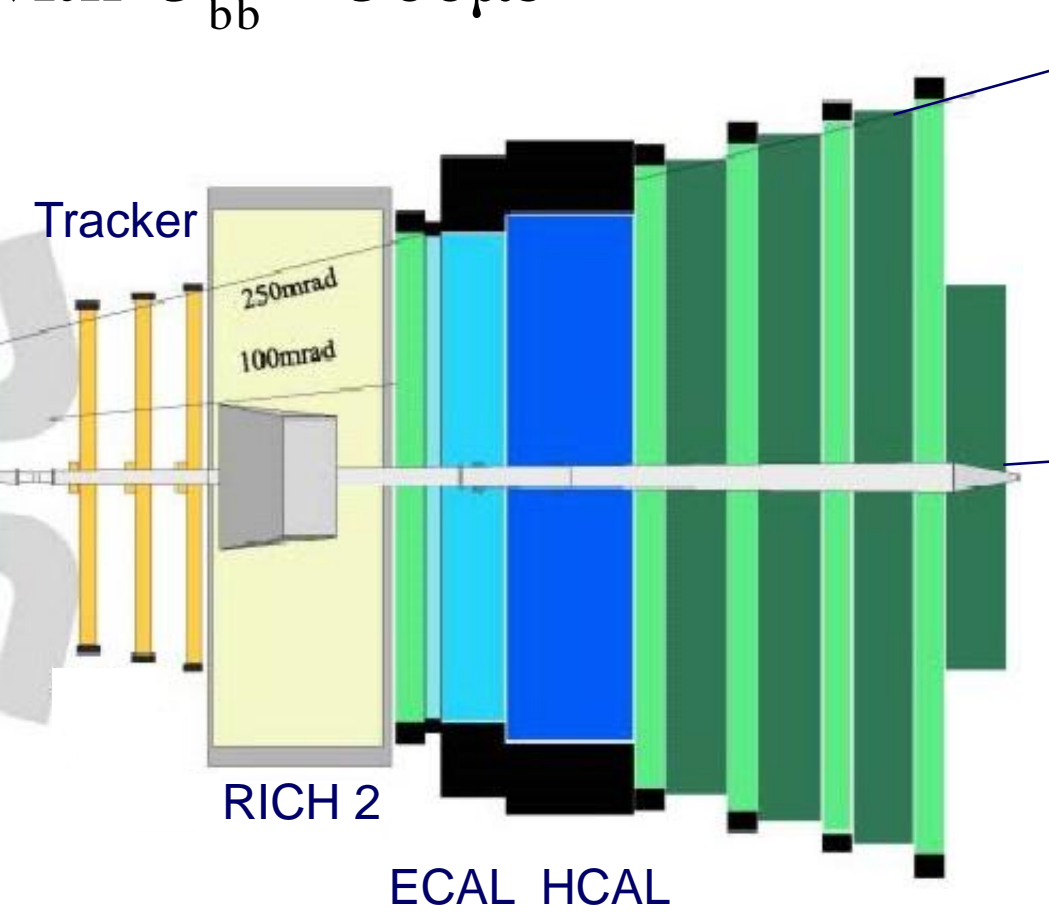

Muons

ECAL HCAL
Angular acceptance

15 - 300mrad
Forward spectrometer 


\section{VErtex LOcator}

- Vertex reconstruction is a fundamental requirement for $\mathrm{LHCb}$

- 21 silicon tracking stations placed along the beam direction

- 2 retractable detector halves for beam injection periods (up to $30 \mathrm{~mm}$ )

Retractable detector halves

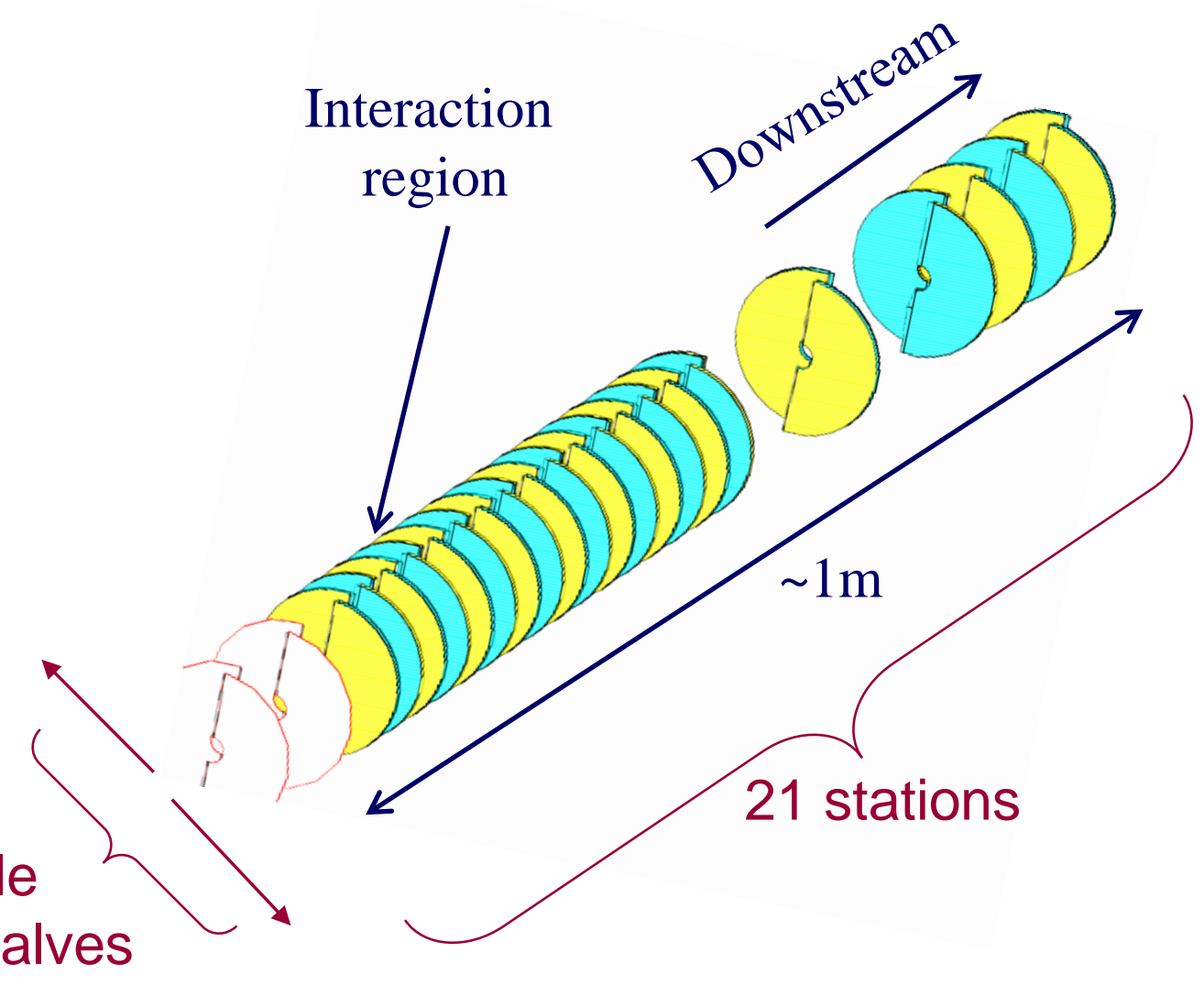




\section{VELO Sensor design}

R-measuring sensor:

(concentric strips)

- 2 sensor types: $\mathrm{R}$ and $\Phi$

- $R$ measuring gives radial position

- $\Phi$ measuring gives an approximate azimuthal angle

- Varying strip pitch

- 40 to $102 \mu \mathrm{m}$ ( $\mathrm{R}$ - sensor)

- 36 to $97 \mu \mathrm{m}$ ( $\Phi-$ sensor $)$

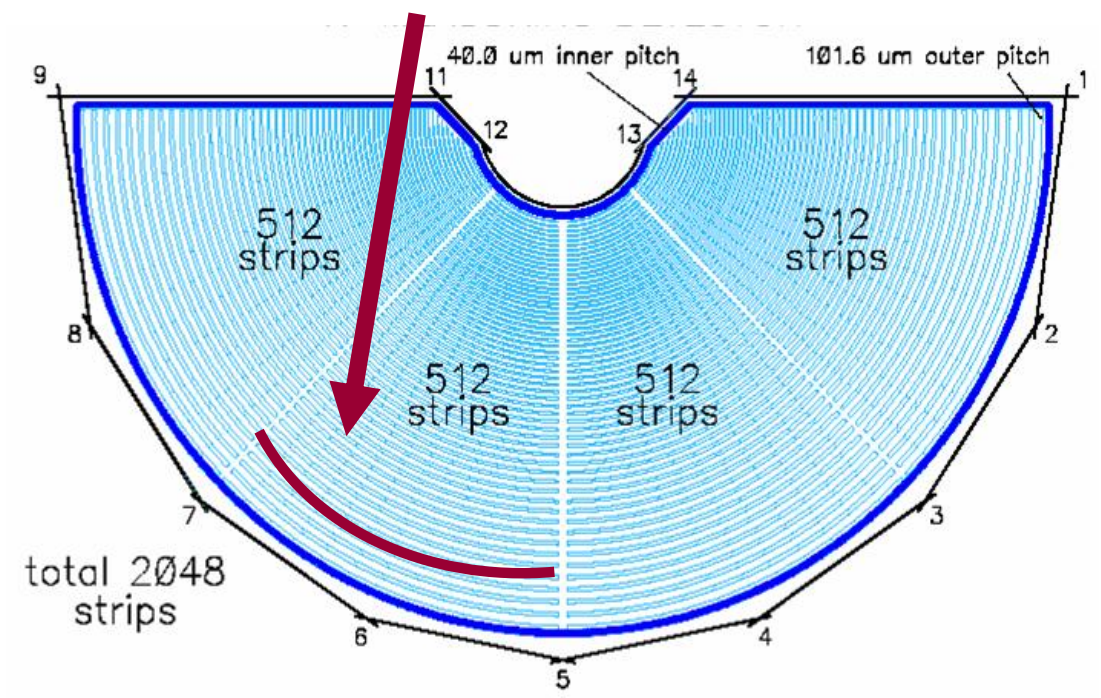

$\Phi-$ measuring sensor:

(Radial strips with a stereo angle)

- First active silicon strip is $8.2 \mathrm{~mm}$ from the beam line

- $\mathrm{n}^{+}$-on-n DOFZ silicon

- minimises resolution and signal loss after type inversion

- Double metal layer for detector readout

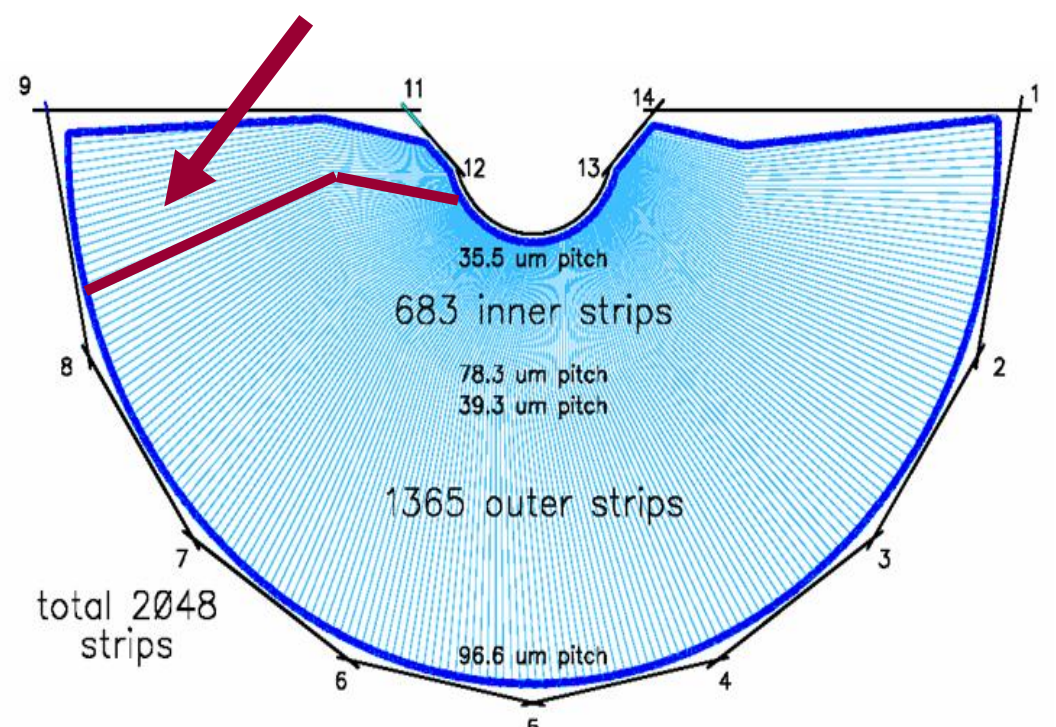


Double sided modules

(1 $x$ R and $1 \mathrm{x}$ $\Phi$ sensor)

Silicon operating temperature $-7^{\circ} \mathrm{C}$ Carbon fibre paddle

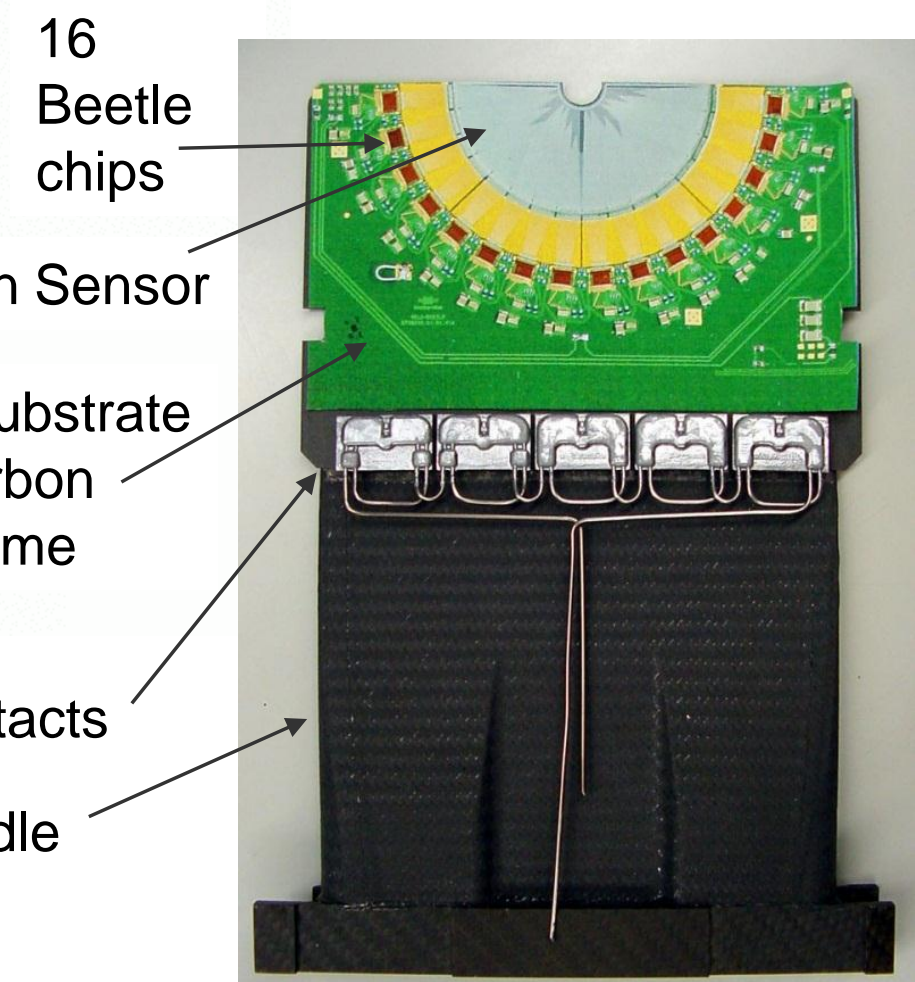




\section{$\underline{\text { VELO environment }}$}

- VELO sensors operate in a harsh non-uniform radiation environment

- fluence to inner regions $1.3 \times 10^{14} n_{e q} / \mathrm{cm}^{2}$

- fluence to outer regions $5 \times 10^{12} n_{e q} / \mathrm{cm}^{2}$

- Estimated to survive 3 years

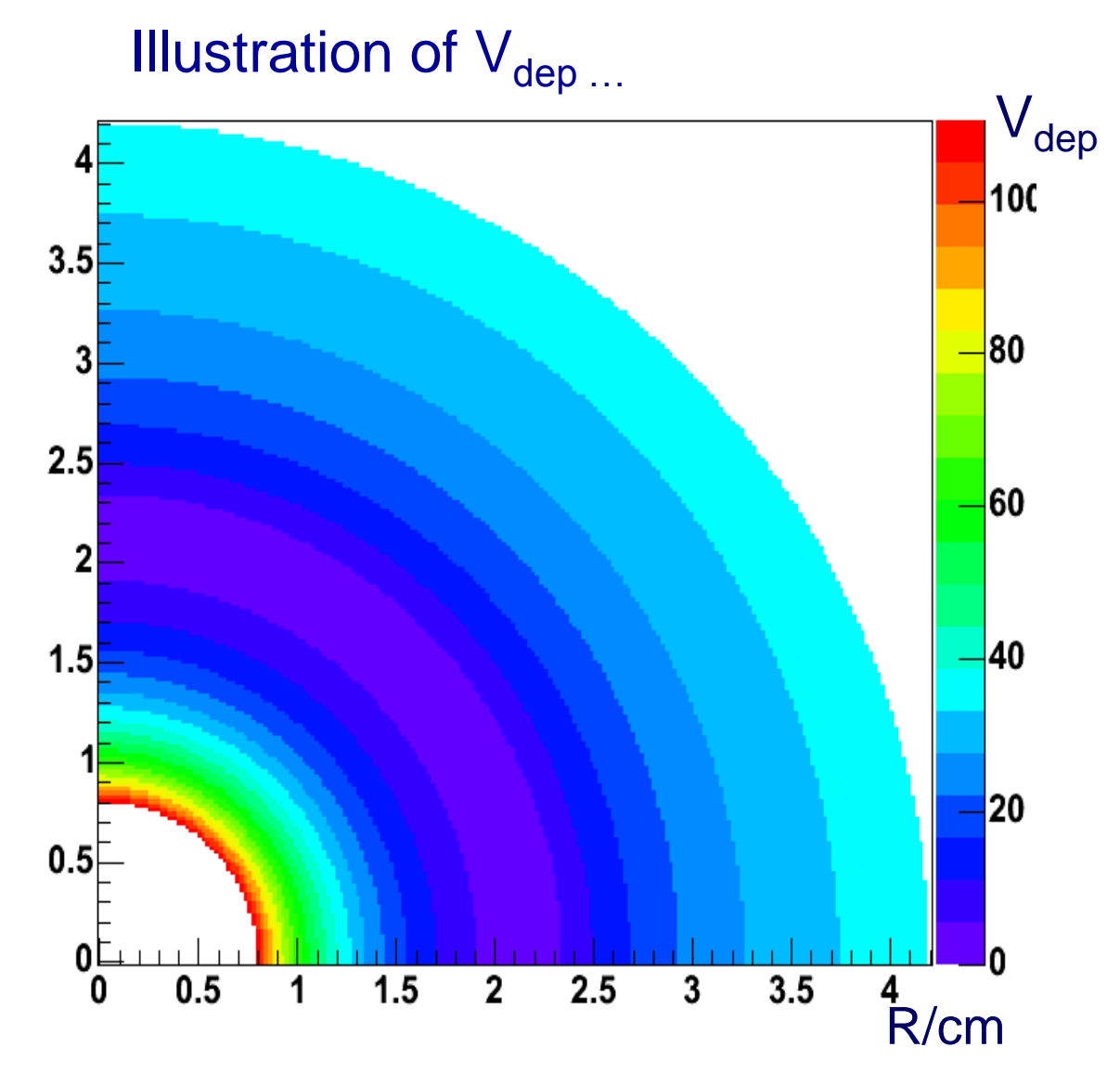




\section{May 2004 test beam results}

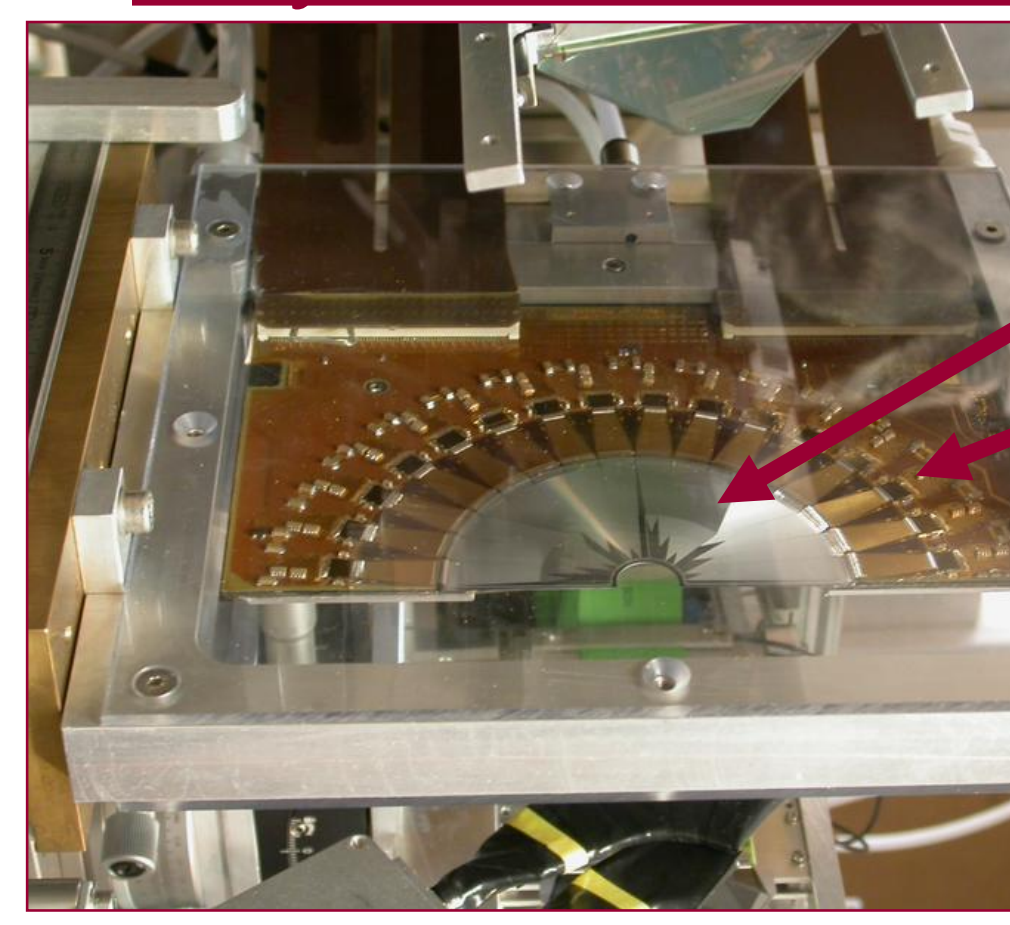

spillover: signal at 25ns after peak in \% of the peak signal

\section{$30 \%$ (100V bias)}

(30\% is the maximum before displaced vertex trigger performance degraded.)

$300 \mu \mathrm{m} \mathrm{n}^{+}-$on- $\mathrm{n} R$ sensor

16 readout chips

$300 \mu \mathrm{m}$ S:N =18:1

$200 \mu \mathrm{m}$ S: $\mathrm{N}=12: 1$

(Beetle 1.3)

Prototype hybrid (K03)

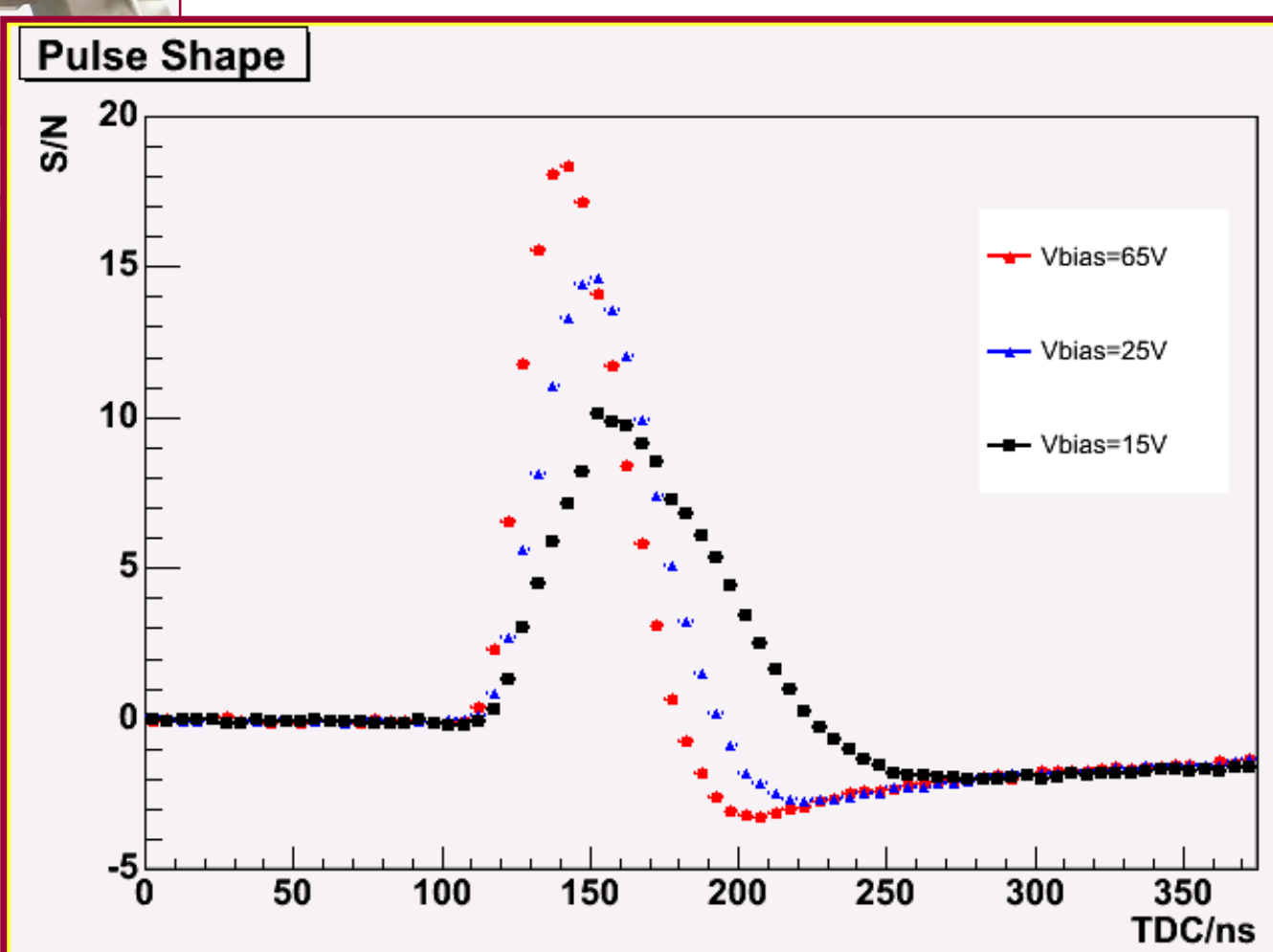




\section{Possible upgrade choices for 2010}

$\mathrm{n}^{+}$-on-p, pixels, 3D, ...many possibilities

- Magnetic Czochralski silicon

- Standard industrial method of producing silicon

- Cheap

- Naturally high Oxygen content

- more radiation hard?

- Test beam at the CERN SPS of a MCz detector ${ }^{*}$ before and after irradiation

- LHC speed electronics $(40 \mathrm{MHz})$

(3 SCTA (analogue) chips)

- $\mathrm{p}^{+}$-on-n MCz material

- Area $_{\text {read out }}=6.1 \times 1.92 \mathrm{~cm}$

- $380 \mu \mathrm{m}$ thick, $50 \mu \mathrm{m}$ pitch

* Many thanks to the Helsinki Institute of Physics for the MCz detector 


\section{MCz test beam results}
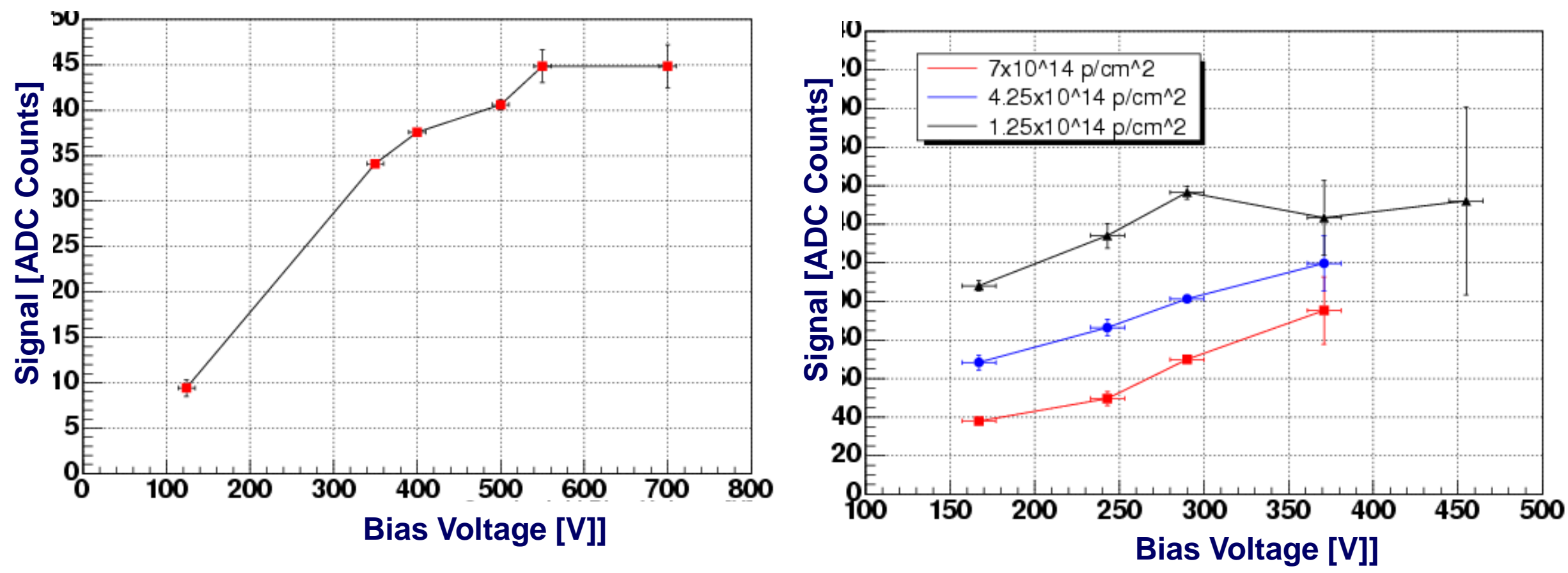

\section{$\checkmark$ Depleted the detector ( 550 V) (CV measured Vdep 420 V)}

$\mathrm{S} / \mathrm{N}>23.5+2.5$

(380 $\mu \mathrm{m}$ thick)

\begin{tabular}{|c|}
\hline$-1.3 \times 10^{14} 24 \mathrm{GeV}$ p/cm² $\mathrm{S} / \mathrm{N}=15$ \\
$-4.3 \times 10^{14} 24 \mathrm{GeV} \mathrm{p} / \mathrm{cm}^{2} \mathrm{~S} / \mathrm{N}=11$ \\
(under depleted) \\
- $7.0 \times 10^{14} 24 \mathrm{GeV} \mathrm{p} / \mathrm{cm}^{2} \mathrm{~S} / \mathrm{N}=7$ \\
(under depleted)
\end{tabular} 


\section{Further MCz benefits}

- The VELO currently uses $\mathrm{n}^{+}-$on-n DOFZ silicon detectors

- This is necessary because we want material where the high field side is always on the strip side in order to prevent loss of resolution and signal

- However, $n^{+}-$on- $n$ is expensive and restricts the choice of processing company (requires double-sided processing)

We have found that $\mathrm{MCz}$ does not type invert using the Transient Current Technique (measured to $5 \times 10^{14} \mathrm{p} / \mathrm{cm}^{2}$ )

*Work performed under the PH-TA1/SD group, CERN (A Bates \& M Moll) 


\section{$\underline{\mathrm{TCT}}$ in $\mathrm{MCz}$}
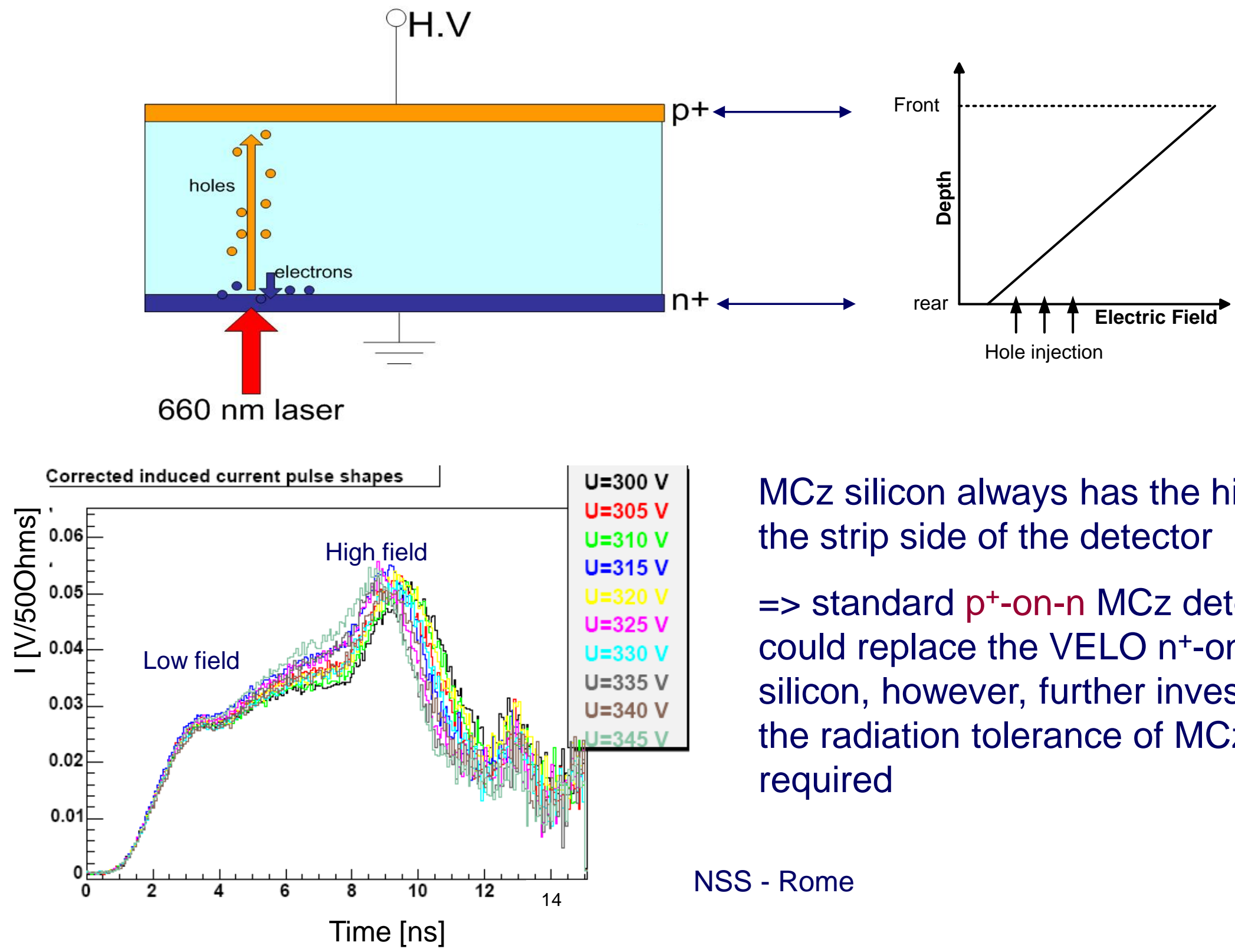

$\mathrm{MCz}$ silicon always has the high field on the strip side of the detector

=> standard $\mathrm{p}^{+}$-on-n MCz detectors could replace the VELO $n^{+}-$on-n DOFZ silicon, however, further investigation of the radiation tolerance of $\mathrm{MCz}$ is required 


\section{$\underline{\text { Status \& Conclusions }}$}

- The VELO is moving from the last prototype testing to sensor production

- first pre-production sensors are just arriving (October 2004)

- test beam of final module configuration in November 2004

- $R \& D$ for possible upgrade solutions is continuing e.g. for $\mathrm{MCz}$

- first operation of full size MCz sensor with LHC speed electronics in test beam

- further test beam studies planned

- non-inversion of $\mathrm{MCz}$ material under radiation demonstrated

- additional microscopic studies underway 


\section{TCT Review}

- $\quad$ Illuminate front $\left(\mathrm{p}^{+}\right)$or rear $\left(\mathrm{n}^{+}\right)$ side of detector with $660 \mathrm{~nm}$ photons

- $\quad$ Light penetrates only a few $\mu \mathrm{m}$ depth

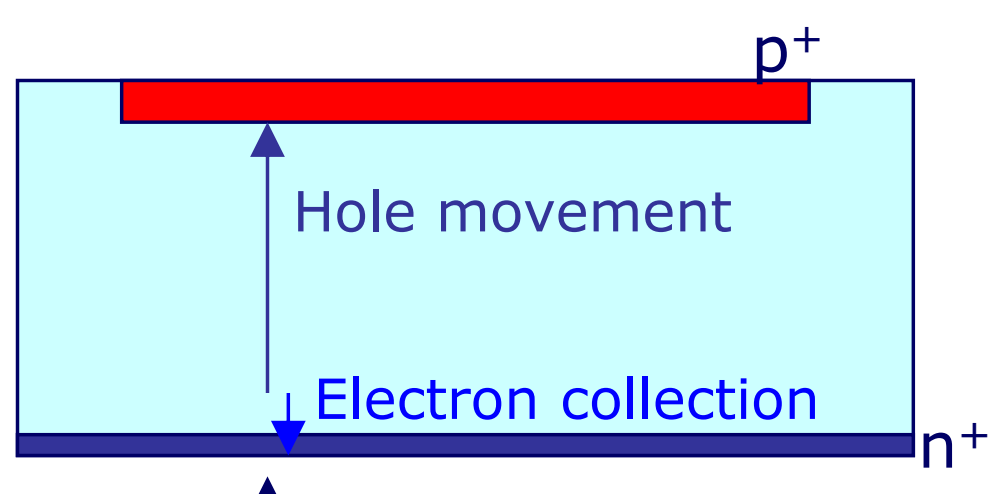

- $\quad I(t)=q E(v(t)) v(t)_{d r i f t}$

- $\quad$ e.g. hole dominated curent (hole injection)

- Illuminate rear $(\mathrm{n}+)$ side of detector

- Ramo's theorem dictates signal will be dominated by one type of charge carrier

$660 \mathrm{~nm}$

laser light

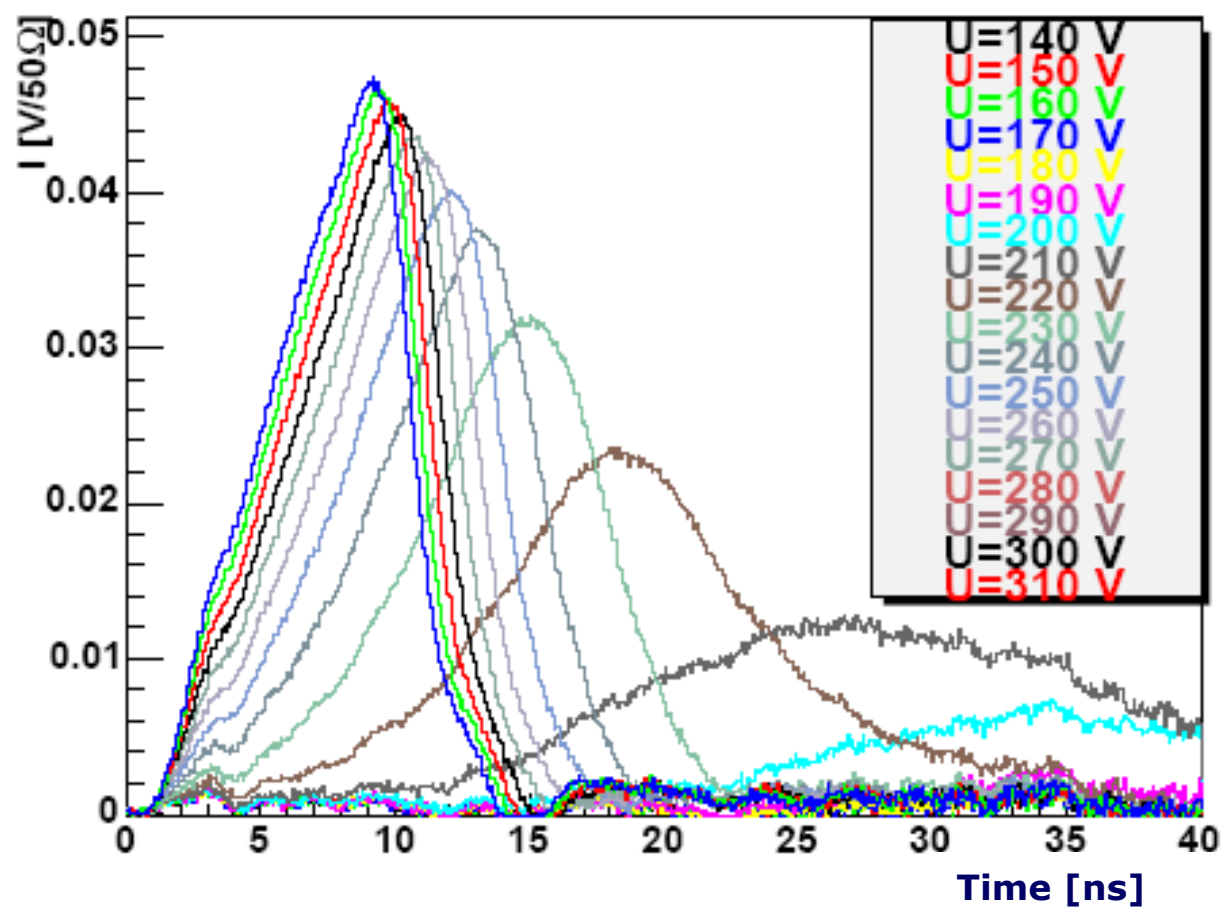




\section{Signal treatment}

- Deconvolution of the true signal from the measured signal

Measured signal $=$ detector signal $\otimes$ transfer function

Transfer function:

$I(t)=\tau_{T C T} / R \times d U_{o s c}(t) / d t+U_{o s c}(t) / R$

$R=50 \Omega$ from input of preamp

$\tau_{\mathrm{TCT}}=\mathrm{RC}_{\mathrm{d}}\left(\mathrm{C}_{\mathrm{d}}=\right.$ detector capacitance $)$

TCT Measurement @ T=+05 C

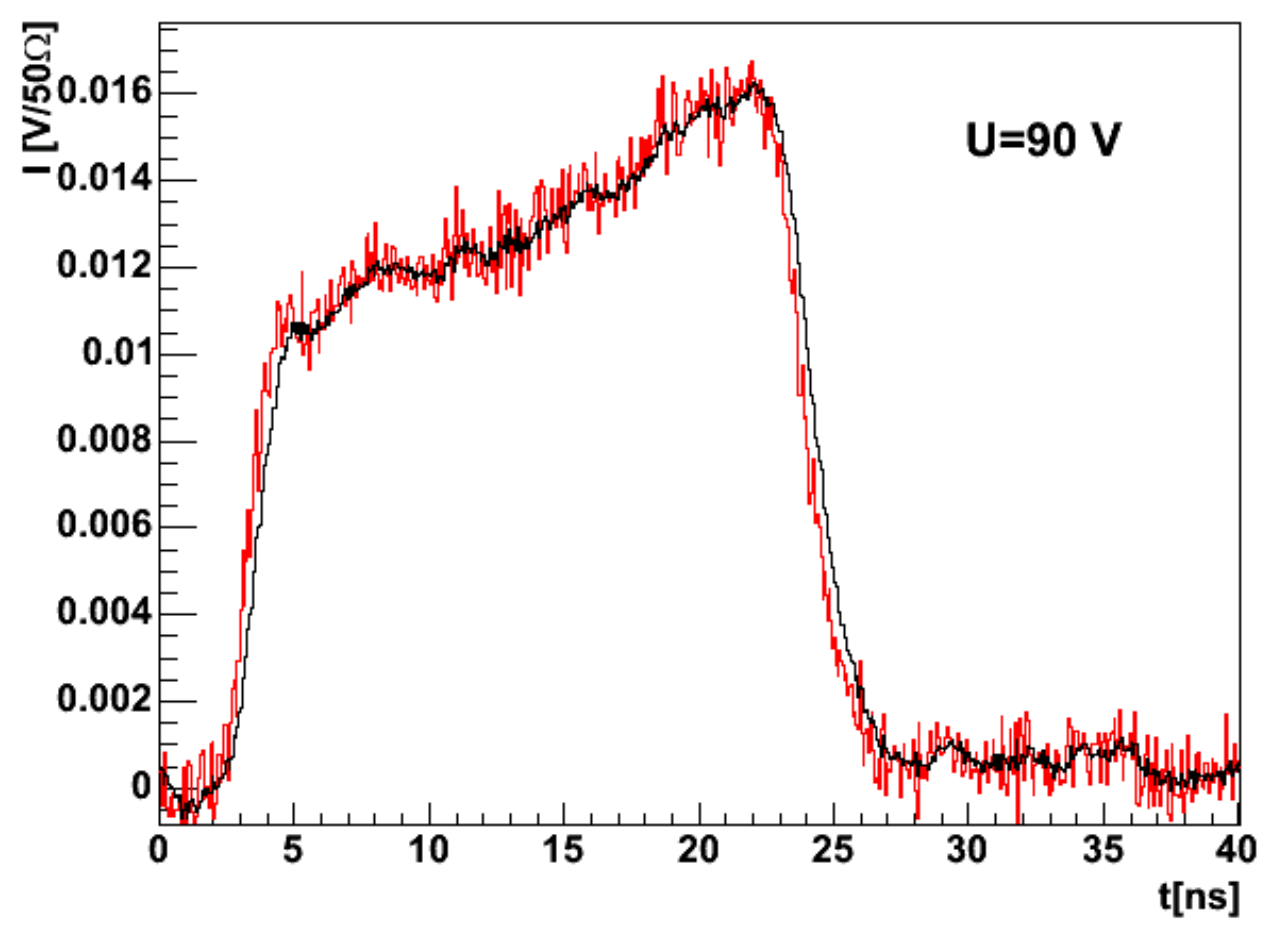

15 


\section{Back up slide 2 - signal examples}

\section{Corrected induced current pulse shapes}

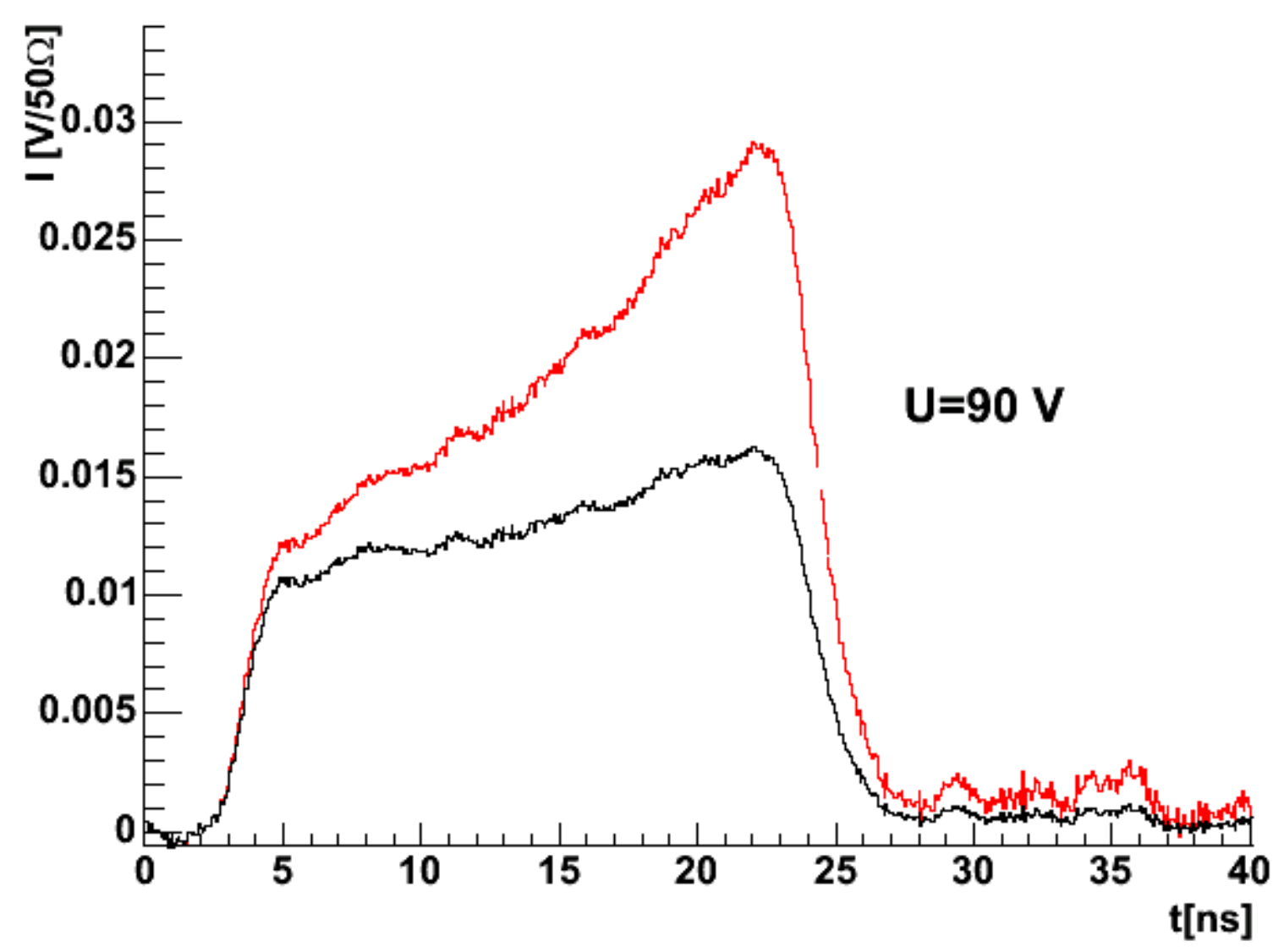

Black = signal as measured on the scope

Red $=$ Trapping corrected signal 


\section{IV/CV analysis}

- $\quad$ CV measurements $-10 \mathrm{kHz}$

- Measurement at room temperature, then corrected to $20^{\circ} \mathrm{C}$

- Guard rings grounded

- Annealed for $4 \mathrm{~min} / 80^{\circ} \mathrm{C}$
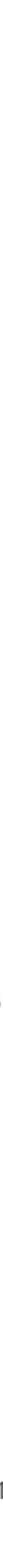


\section{$\underline{\text { TCT Diagram }}$}

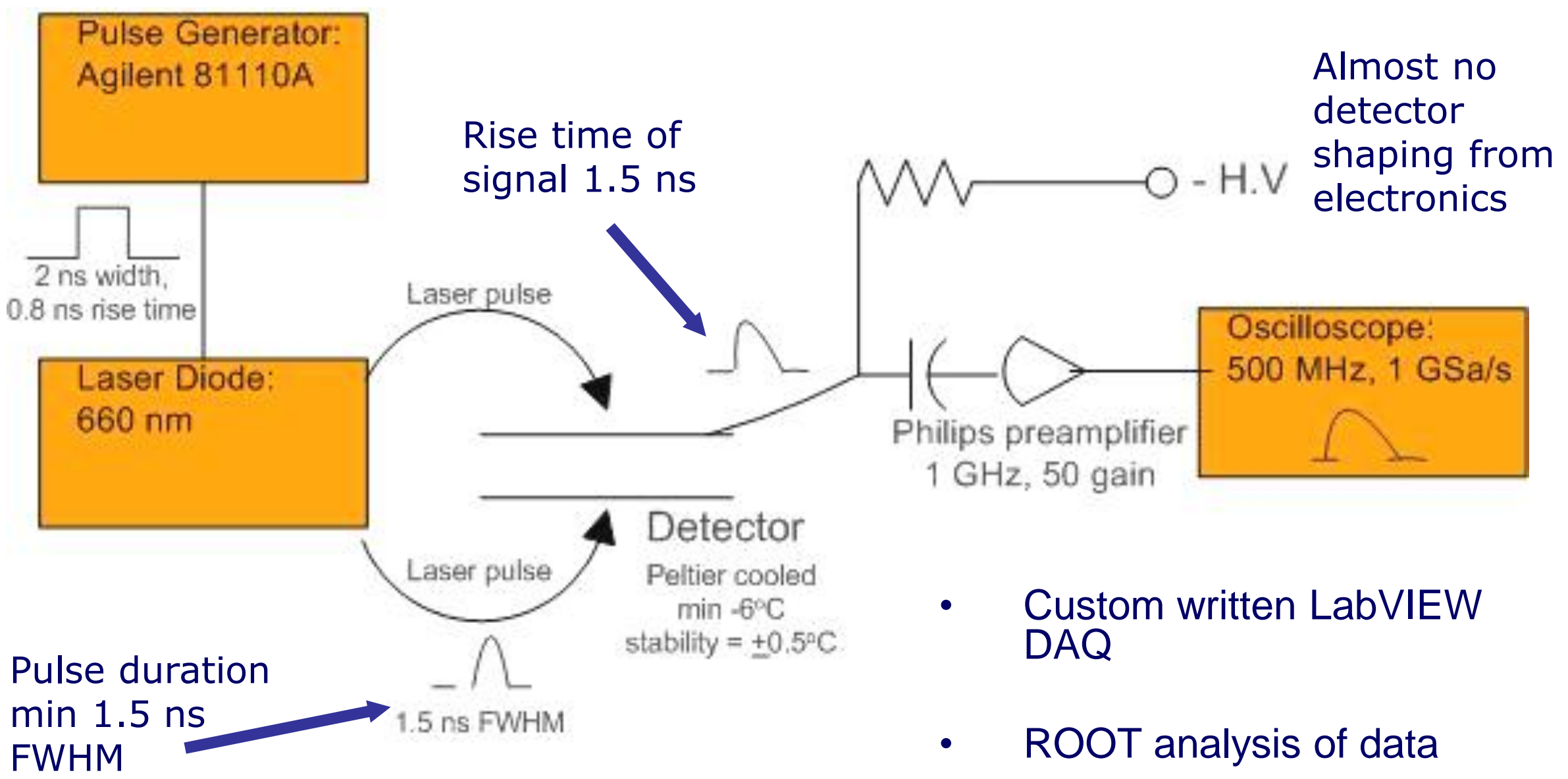




\section{$\underline{\mathrm{MCz}}$}
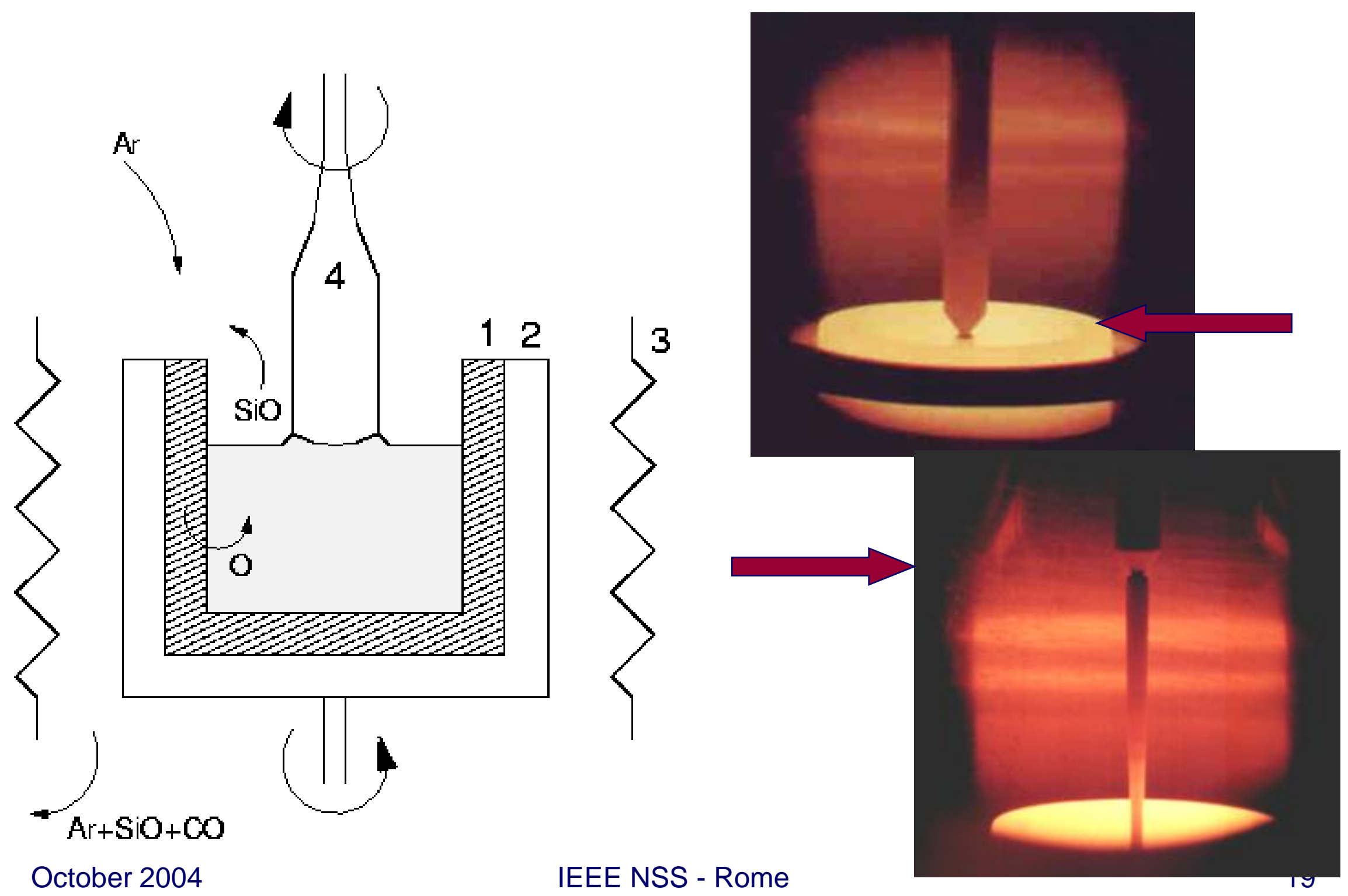

October 2004

IEEE NSS - Rome 


\section{Beam Test: Setup}

test module

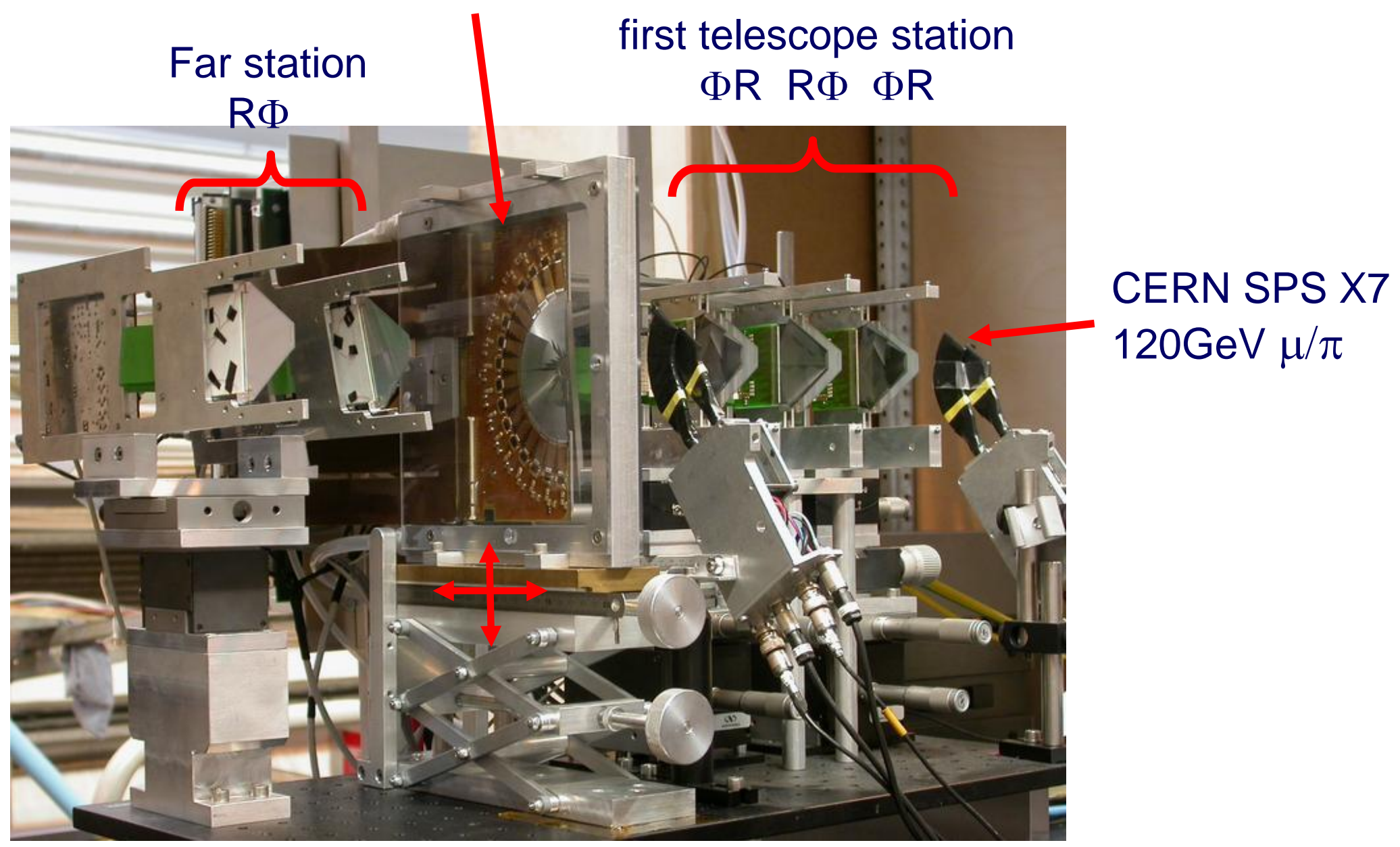




\section{Modules recently tested}

-in Summer 2003:

-200 $\mu$ m thick PR03

-n-on-n R-sensor

-1 Beetle1.2 on PCB

-1 chip region read out

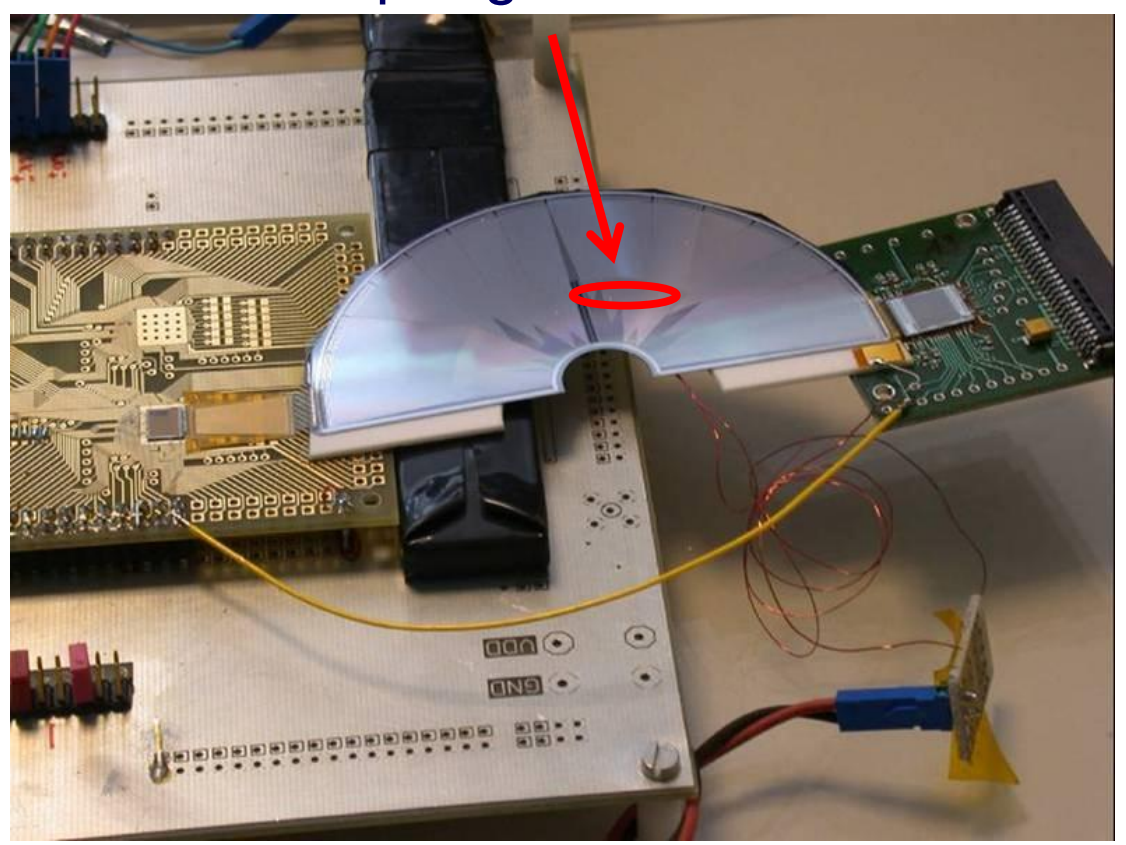

Data with tracks in telescope single sample -in June 2004:

-300 $\mu$ m thick PR03

•n-on-n R-sensor

-fully populated K03 hybrid

-Beetle1.3 tested many regions read out

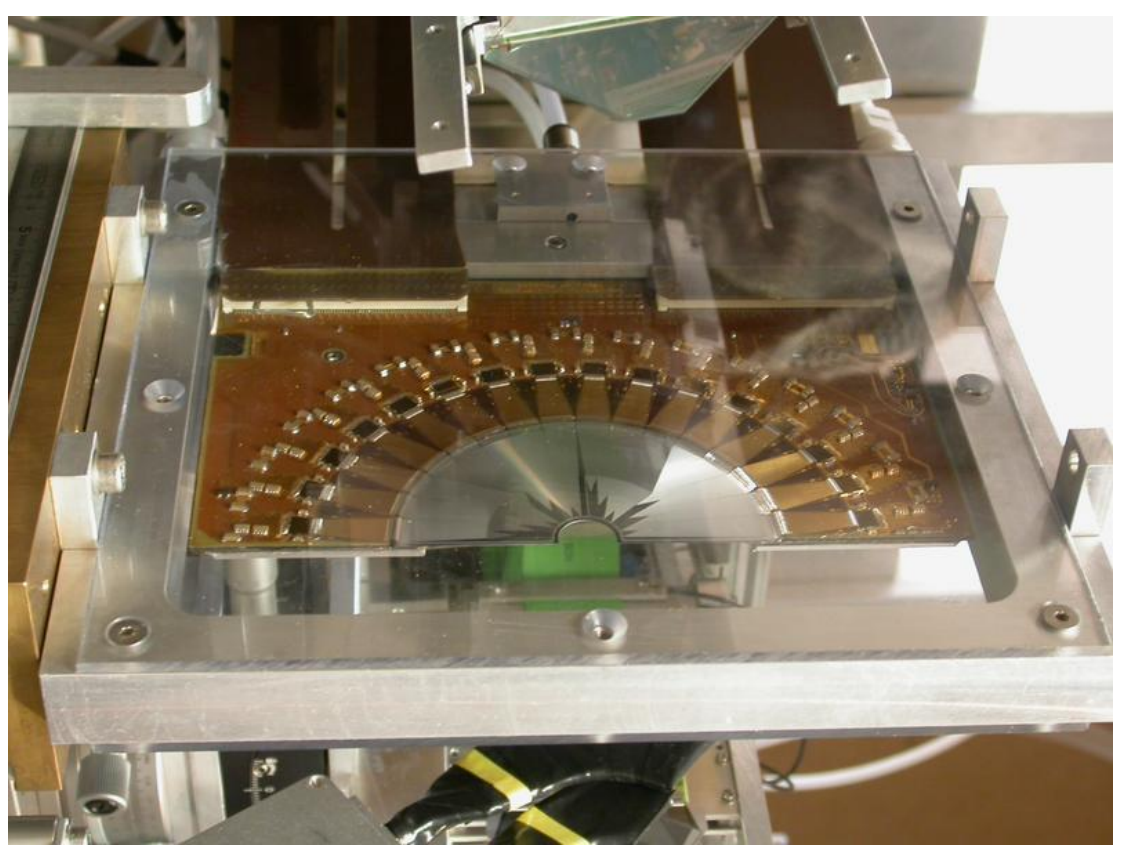

track data not yet analysed - use stand-alone 15 consecutive samples read out 


\section{Beam Test 2003 - Results}

$\mathrm{S} / \mathrm{N}$ and Spillover for a set of Beetle Bias settings

Minimum at LHCb startup

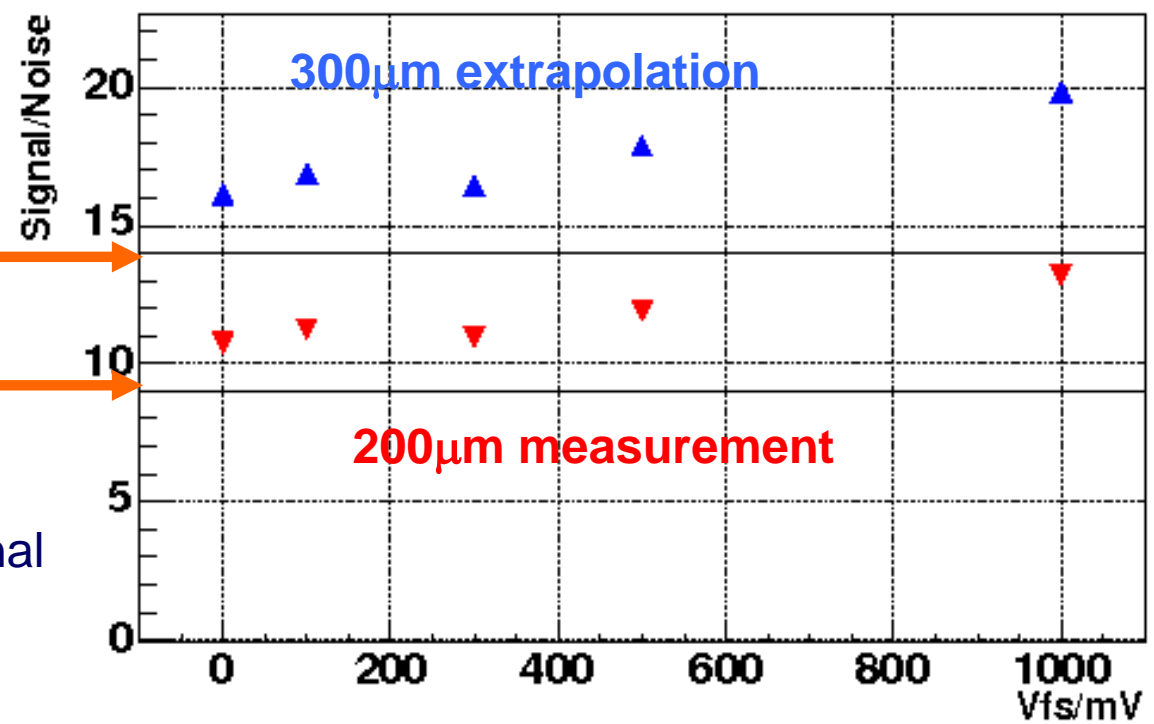

spillover: signal at $25 \mathrm{~ns}$ after peak in $\%$ of the peak signal

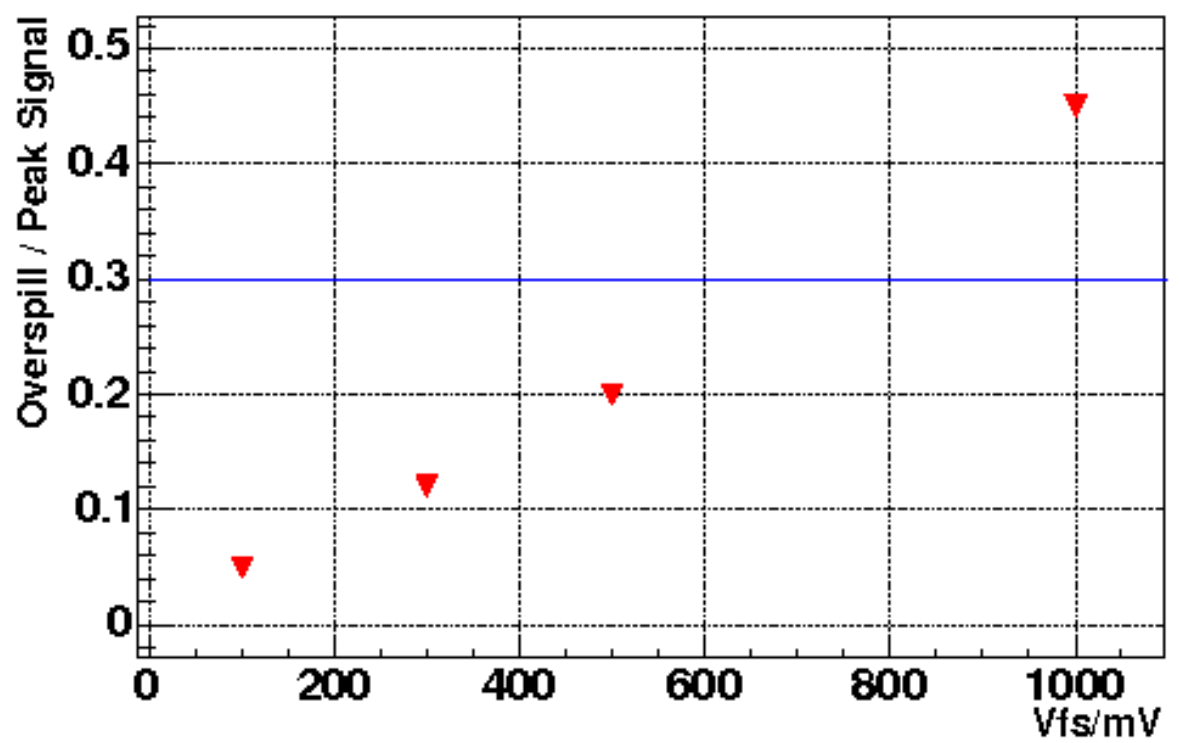

Maximum requirement from Trigger

$\mathrm{S} / \mathrm{N}$ for $200 \mu \mathrm{m}$ at the lower side

$\rightarrow$ test $300 \mu \mathrm{m}$

October 2004

IEEE NSS - Rome 22 Back up slide from D Eckstein, Vertex 2004 


\section{new 2004 Data- Results}

$\rightarrow \mathrm{S} / \mathrm{N}$ for $300 \mu \mathrm{m}$ agrees with scaled $200 \mu \mathrm{m}$
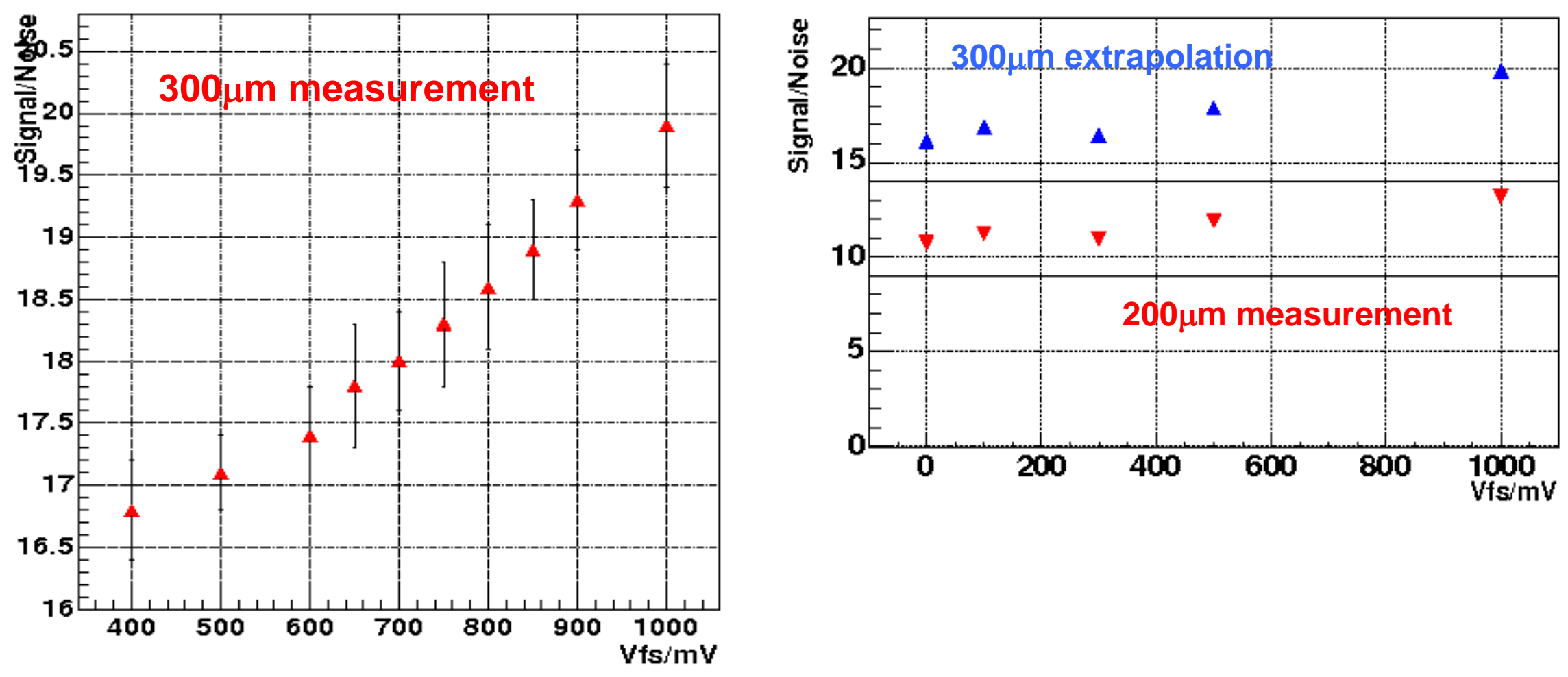

$\rightarrow$ the K03 hybrid (and other components in the chain) do not add noise $\rightarrow \mathrm{S} / \mathrm{N}$ in agreement with requirements - should we use the thicker sensors? 


\section{new 2004 Data- Results}

medium strip length
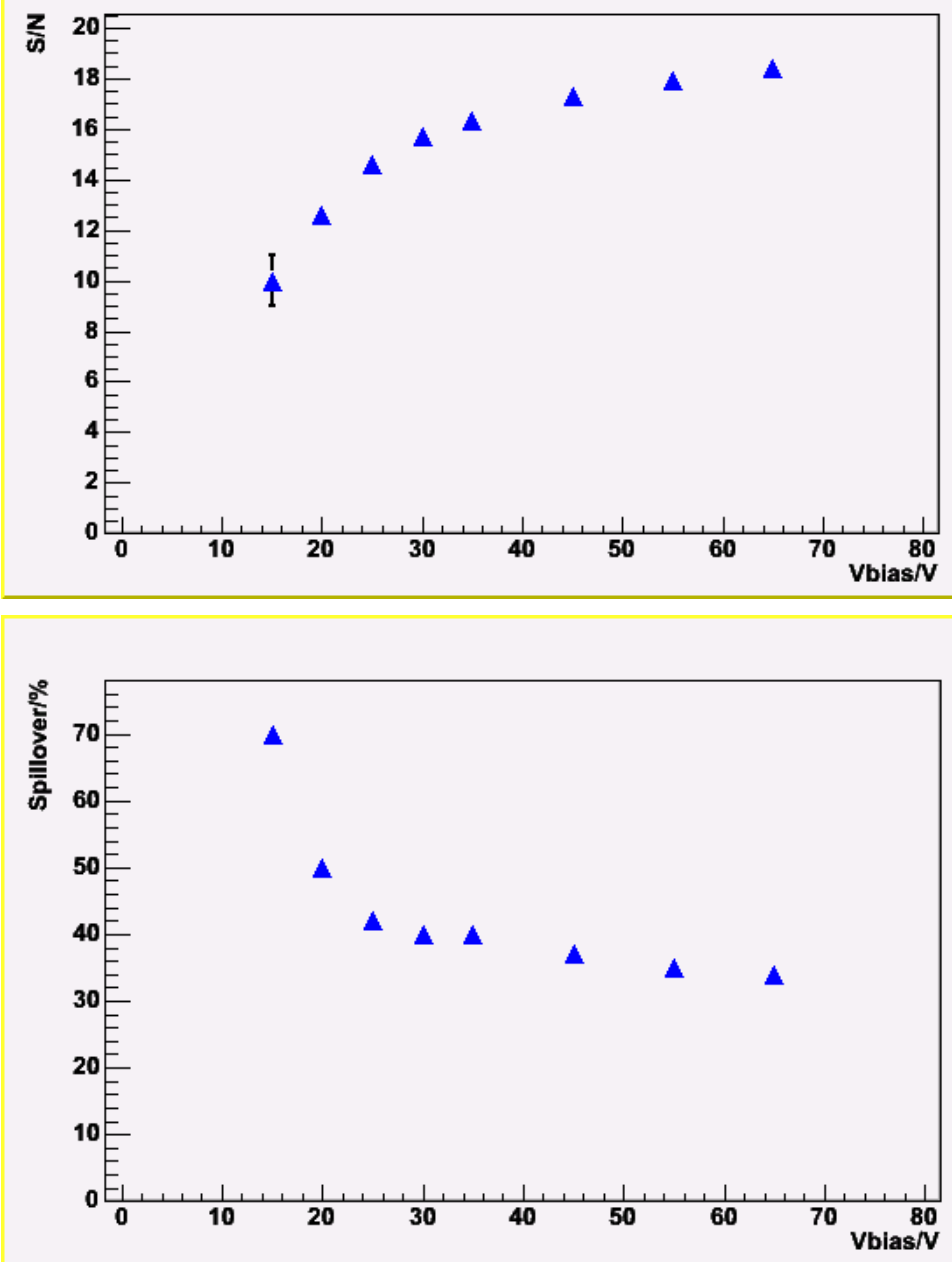

shortest strips
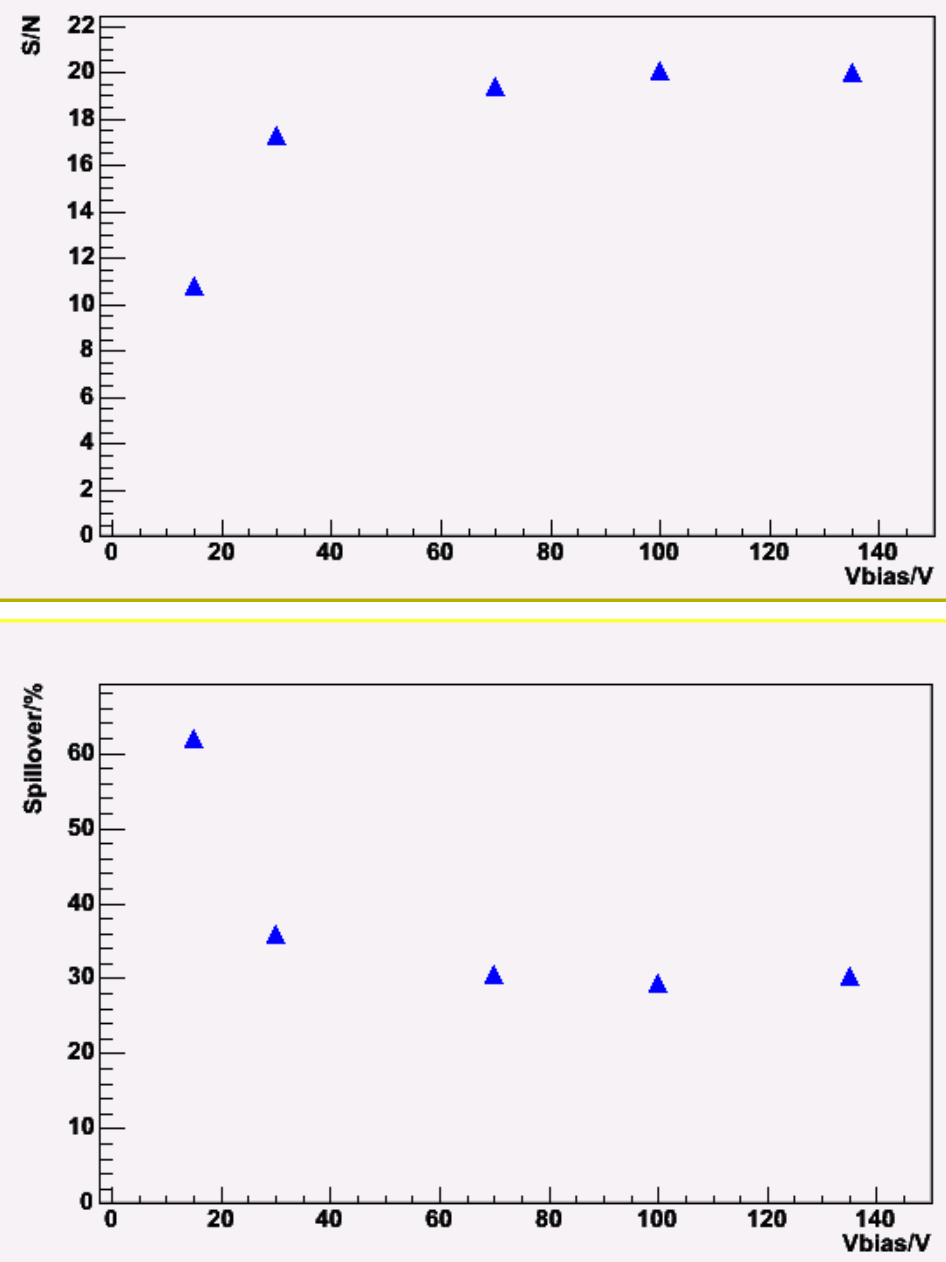

it is safer to run at $\sim 100 \mathrm{~V}$ 